\title{
EKSTRAKSI BUAH SEBAGAI PEWARNA KAIN KATUN DI PUSAT STUDI BATIK UNIVERSITAS COKROAMINOTO YOGYAKARTA
}

\author{
Riska Kurnia *)
}

\begin{abstract}
This research aims to determine the level of colorfast resistance to sunlight and ash off soap test, which is produced from pitaya natural dyeing with fixation of chalk, alum, lotus, coconut sugar, and lime.

Type of Research and Development ( $R \& D$ ) is used in this research. In this study, some approaches which are taken such as: 1)Preliminary Studies (Devine) on materials to be processed: primisima material or a kind of cotton fabric, pitaya, dragon fruit peel and other auxiliaries. 2) Planning (Design) includes designing action steps which will be done by preparing tools as the first step. 3. Development: processing raw materials such as pitaya as the natural dye with fixation of chalk, alum, lotus, lime, and coconut sugar.

The results show a different color from any given fixation. Pitaya natural dye with lotus fixation, testing of colorfast resistance to sunlight, shows the best score of 5 and the color is yellowish beige. Pitaya with chalk fixation, the score is 5, indicates the color of light cream almost white. Pitaya extraction with lotus fixation has score 5 and a beige brown color. Pitaya peels with lotus fixation has score 5 and a beige fawn color. Pitaya peels with the sugar fixation, score of 5, resulting a light cream color. The test results of colorfast resistance to wash off soap test, the best results are shown in Pitaya fixation with lotus, with score 4 and a yellowish beige color. Pitaya extract with lotus fixation has score 4 and the color is yellowish beige. Pitaya peels with lotus fixation has score 4, resulting a yellowish beige color.
\end{abstract}

Keywords: Pitaya, alum fixation, chalk, lotus, coconut sugar, lime.

\section{ABSTRAK}

Penelitian ini bertujuan untuk mengetahui tingkat ketahanan luntur warna pada uji sinar matahari dan uji cuci sabun. Yang dihasilkan dari pewarnaan alami buah Naga dengan fiksasi kapur, tawas, tunjung, gula jawa dan jeruk nipis.

Jenis penelitian yang digunakan adalah Research and Development (R\&D). Dalam penelitian ini pendekatan yang dilakukan yaitu: 1 ) Studi Pendahuluan (Devine) tentang bahan yang akan diolah: bahan primisima atau jenis bahan kain katun, buah naga, kulit buah naga dan bahan bantu lainnya. 2) Perencanaan (Desain) meliputi merancang langkah kerja yang akan dilakukan dengan mempersiapkan alat sebagai langkah awal. 3) Pengembangan

*Riska Kurnia, Pengelola Pusat Studi Batik Universitas Cokroaminoto Yogyakarta 
(Development): mengolah bahan baku berupa buah naga sebagai bahan baku pewarna alami dengan perlakuan fiksasi kapur, tawas, tunjung, jeruk nipis, gula jawa.

Hasil uji yang dilakukan menunjukkan warna yang berbeda dari setiap fiksasi yang diberikan. Adapun pada pewarna alami buah Naga dari pengujian ketahanan luntur sinar matahari yang menunjukkan score terbaik yaitu yang terdapat pada buah Naga dengan fiksasi tunjung menunjukkan score 5, warna yang dihasilkan krem kekuningan. Buah Naga dengan fiksasi kapur dengan score 5 menunjukkan warna krem muda hampir putih. Buah Naga Ekstraksi dengan fiksasi tunjung dengan score 5 warna yang dihasilkan krem coklat muda. Kulit buah Naga dengan fiksasi tunjung score yang diperoleh 5 , warna yang dihasilkan krem coklat kekuningan. Kulit buah Naga dengan fiksasi gula jawa score 5 dengan warna yang dihasilkan krem muda. Hasil Uji tahan Luntur pada Pencucian Sabun hasil terbaik ditunjukkan pada buah Naga dengan fiksasi tunjung score 4, warna yang dihasilkan krem kekuningan. Ekstrak buah Naga dengan fiksasi tunjung score 4, warna yang dihasilkan krem kekuningan. Kulit buah Naga dengan fiksasi tunjung score 4, warna yang dihasilkan krem kekuningan.

Kata Kunci : buah Naga, Fiksasi tawas, kapur, tunjung, gula jawa, jeruk nipis

\section{PENDAHULUAN}

Warna alami merupakan warna yang diperoleh dari bahan-bahan alam seperti halnya pada daun, batang, buah, kulit akar pohon, dll. Warna alami digunakan sudah sejak ditemukannya bahan pakaian yang digunakan oleh nenek moyang. Bahan warna alami mudah ditemukan dan jumlahnya relatif lebih banyak. Contohnya disekitar lingkungan kita banyak terdapat tumbuhan yang memiliki kandungan warna alami.

Pada pengolahan warna alami memunculkan warna yang sukar ditemui karena faktor keragaman tanaman, jenis tanah disetiap daerah, temperatur atau suhu disetiap daerah memiliki iklim yang berbeda-beda. Sifat warna alami ramah lingkungan dan tidak mencemari lingkungan. Warna-warna yang dihasilkan memiliki warna yang unik yang berbeda dengan warna-warna yang lain yang pernah dihasilkan.

Seiring dengan perkembangan zaman bahan pewarnaan bahan kain mengalami perkembangan yang bermula dari warna alami mengalami perkembangan sejak ditemukannya warna sintetis pada tahun 1911 di Jerman dan dibawa oleh bangsa Belanda ke Indonesia pada tahun 1930, warna alami mulai banyak ditinggalkan karena warna sintetis yang digunakan cara pengolahannya lebih praktis dan memiliki banyak ragam warna (Murtihadi dan Mukminatun, 1979). Beberapa jenis warna sintetis yang sering digunakan antara lain Naptol, Remasol, Indigosol, Rapit, dll. Berbagai macam warna sintetis yang digunakan memiliki teknik yang berbeda-beda. Warna sintetis memiliki dampak yang buruk yaitu dapat mencemari lingkungan dan dapat menyebabkan penyakit kanker kulit. Metode akstraksi warna indigo (kimia) 
mengakibatkan hal yang kurang menguntungkan bagi si pemakai (Sugeng Sudiatso, 1999).

Terkait dengan dampak bahwa warna sintetis dapat mengakibatkan pencemaran lingkungan maka dalam hal ini dilakukan pembahasan warna alami melalui penelitian yang berasal dari bahanbahan alami dari tumbuhan, dimana warna alami merupakan warna yang ramah lingkungan. Selain itu warna alami dapat digunakan sebagai pupuk yang dapat menyuburkan tanah. Salah satu pewarna yang digunakan untuk penelitian yaitu mengenai buah Naga, dimana buah Naga ini memiliki kandungan warna yang menarik. Warna yang terdapat dari buah Naga yaitu warna merah, ungu, putih. Warna buah Naga ini biasa digunakan sebagai bahan pewarna makanan, sedangkan untuk bahan pewarna pada kain belum pernah dilakukan penelitian. Untuk itu dalam penelitian ini penulis mencoba untuk meneliti warna yang terdapat pada warna buah Naga sebagai bahan pewarna kain. Warna buah Naga yang digunakan yaitu warna merah dimana pada buah Naga yang berwarna merah mudah ditemukan. Penelitian ini untuk mengetahui hasil warna buah Naga setelah diujikan pada fiksasi kapur, tawas, tunjung, gula jawa dan jeruk nipis.

\section{METODE}

Metode yang digunakan adalah Research and Development (R\&D), yaitu untuk mengembangkan zat warna alami ke dalam pewarnaan kain melalui fiksasi berupa kapur, tawas, tunjung, jeruk nipis dan gula jawa. Langkah-langkah yang dilakukan dalam penelitian ini antara lain:

1) Studi Pendahuluan yaitu untuk mengetahui bahan yang digunakan yaitu pada buah Naga, kulit buah Naga serta zat fiksasi; 2) Perencanaan (Desain) yaitu merancang bahan baku dengan menentukan ukuran; 3) Pengembangan (Development), mengembangkan bahan baku kedalam bermacam-macam fiksasi; 4) Validasi yaitu penelitian dengan perencanaan untuk mengetahui hasil warna dan juga hasil ketahanan luntur warna.

Variabel untuk mengetahui perlakuan pengukuran yaitu dengan menggunakan variabel bebas dan variabel terikat. Variabel bebas adalah variabel yang variasinya mempengaruhi variabel lainnya. Variabel yang dapat diukur dan diamati. Variabel ini dari penggunaan warna alami buah Naga dengan perlakuan fiksasi yang bervariasi. Variabel terikat yaitu variabel yang diukur untuk mengetahui besarnya efek atau variabel kontrol akan timbul dari dalam hubungan fungsional sebagai pengaruh dari variabel bebas.

Validitas Penelitian, merupakan suatu ukuran untuk menentukan tingkat kevalidan dan kesahihan suatu instrument. Dalam penelitian ini berfungsi untuk mengendalikan varian agar diperoleh optimasi yang berimbang antara validitas luar dan validitas dalam (Mukayat Brotowidjoyo, 1991:63).

Validitas dalam (interval validity) adalah ukuran sejauh mana perubahan yang diamati dalam penelitian (penelitian Eksperimental) yang benar-benar hanya terjadi karena pengaruh dari faktor lain (validitas luar). Validitas dilakukan dengan 
alat yang telah ditentukan, menggunakan bahan baku yang telah ditentukan, fiksasi yang telah ditentukan, takaran pembanding air dengan bahan (volt), berat kain, jenis pewarna yang digunakan, proses pengerjaan yang sama.

Validitas luar (enternal validity) yaitu untuk mengukur sejauh mana hasil penelitian dapat digeneralisasilan pada populasi atau asal sampel. Validitas luar dilakukan diluar dari pengawasan pembimbing, melainkan menguji sampel pada kain yaitu dengan pembimbing laboratorium, penguji dilakukan dengan penyusun mengikuti prosedur pengujian.

Uji Eksperimen dan Sampel Uji, Bahan uji yang digunakan adalah kain primisima, dimana kain primisima ini memiliki sifat hygroskopis yaitu suatu zat yang dapat menyerap air dari lingkungannya. Diujikan dengan menggunakan zat warna alami buah Naga, kulit buah Naga dengan perlakuan fiksasi yang bervariasi yaitu dengan fiksasi kapur, tawas, tunjung, jeruk nipis dan gula jawa. Pengujian yang dilakukan yaitu dengan uji ketahanan luntur sinar matahari dan uji ketahanan luntur cuci sabun.

Sampel yang diujikan dengan menggunakan ukuran $5 \mathrm{~cm} \times 10 \mathrm{~cm}$ perukuran sampel sedangkan alat yang digunakan dalam pengujian ketahanaan luntur terhadap sinar matahari dan cuci sabun yaitu Gray Schale.

\section{PEMBAHASAN}

Hasil eksperimen pewarnaan alami dari buah Naga, Kulit buah Naga dengan fiksasi kapur, tawas, tunjung, jeruk nipis, gula jawa antara lain:

\section{bahan dan alat}

Bahan yang digunakan antara lain kain katun Kain katun, Kain katun tergolong serat sellulosa atau dari tumbuhan, serat katun merupakan serat yang pendek, serat ini berasal dari kapas (Santika Dewi, 2005). Serat katun mempunyai banyak gugusan $\mathrm{OH}$ dimana $\mathrm{O}$ bersifat elektro-negatif kuat dan $\mathrm{H}$ bersifat elektro-positif lemah, sehingga serat dalam rendaman air bermuatan negatif karena terdapat $\mathrm{OH}$. Dan serat ini banyak terdapat deretan cellulosa atau polimir-glukosa (Sewan Susanto, 1974). Adapun sifat-sifat kain katun menurut Eny Zuhni Khayati (1997) antar lain: a) Berserabut pendek 20$55 \mathrm{~mm}$; b) Kuat dalam keadaan basah kekuatan bertambah $25 \%$. Kekuatan serat dapat bertambah dalam larutan costic soda disebut memeter. Lapisan serat mengandung zat lilin (kutikula). Zat ini dapat dihilangkan dengan zat kimia (costik soda). Sangat hygroskopis / mudah menyerap air. Tahan lindi (zat pencemar organik yang mengandung karbon) tahan panas, tahan ngengat. Tidak tahan terhadap jamur. Menyusut pada waktu pencucian. Kekuatan serat menurun oleh zat pengoksidasi karena terjadi aksi sellulosa, hal ini sering terjadi dalam proses pemutihan yang berlebihan, penyinaran, penyimpanan dalam keadaan lembab atau pemanasan yang lama pada suhu diatas $140^{\circ} \mathrm{C}$. Sifat katun atau mori memiliki sifat yang dapat diberikan perlakuan pewarnaan salah satu sifat yang terdapat pada serat katun yaitu adanya sifat hygroskopis, sifat kain yang dapat menyerap air dalam pewarnaan.

Soda Abu, merupakan zat yang berupa serbuk putih yang dapat berfungsi 
sebagai zat untuk memordan. Zat ini terdapat suasana alkali yang dapat membantu dalam memberikan ikatan oksida logam pada kain sehingga dapat membantu kain dalam menyerap warna.

Tawas berbentuk kristal putih terdapat kandungan ion logam aluminium dengan simbol (SO4). Berfungsi untuk proses mordanting yaitu memberikan ikatan oksida logam dengan bercampurnya soda abu sedangkan dalam proses fiksasi akan membangkitkan warna dan juga akan mengunci warna agar tidak mudah luntur.

TRO berupa serbuk kecil yang dapat digunakan dalam pembasah pada kain sebelum dilakukan pencelupan. TRO dapat membantu membuka serat kain sehingga dapat membantu pewarnaan mudah masuk pada serat kain.

Buah Naga merupakan bahan zat warna alami yang akan di olah untuk pewarnaan alami yaitu melalui ekstraksi. Zat warna ini memiliki zat anosianin suatu zat yang memberikan warna pada jenis tumbuhan. Warna yang terdapat pada tumbuhan dari zat anosianin adalah warna merah, oranye, ungu dan biru sedangkan pada warna buah Naga ini merah dan ungu. Salah satu yang akan digunakan dalam penelitian ini dengan menggunakan warna buah Naga merah.

Alat yang digunakan dalam proses warna alam antara lain 1) Timbangan analitik untuk mengukur /menimbang jenis bahan; 2) Gelas ukur 1000 ml untuk menentukan takaran zat cair dalam liter, saringan untuk menyaring zat cair setelah proses ekstraksi; 3) Kompor untuk memanaskan proses mordanting kain dan proses ekstrasi warna alami; 4)Panci untuk tempat; 5) kain waktu mordan dan tempat warna alami proses ekstraksi; 6) Ember untuk tempat saringan warna alami dan tempat pencelupan warna alami; 7) Sarung tangan digunakan waktu proses pencelupan warna alami; 8) Kertas $\mathrm{pH}$ untuk mengukur tingkat $\mathrm{pH}$ pada zat warna alami. Hal ini untuk menentukan warna yang dapat digunakan yaitu terdapat pada nilai 7,5.

\section{Pengolahan Bahan}

Perendaman kain dengan larutan TRO selama satu malam. Hal ini untuk menghilangkan kotoran yang terdapat pada kain. Kemudian cuci bersih dan dikeringkan.

Mordan pada Kain Katun, Pemordanan kain untuk memberikan ion oksida logam yaitu dengan soda abu 2 gr/liter dan tawas $6 \mathrm{gr} /$ liter larutan mordan dididihkan kemudian kain dimasukkan dan ditunggu hingga 1 jam dalam didihan kemudian kompor dimatikan dan kain tetap berada dalam panci selama 1 malam, pagi harinya kain dicuci bersih dengan air biasa tanpa zat bantu lainnya, kain dikeringkan. Kain siap diberikan pewarnaan.

\section{Proses Pencelupan}

Sebelum dilakukan pencelupan pada kain bahan warna alami melalui proses ekstraksi yaitu untuk memunculkan warna yang terdapat pada bahan baku warna alam. Adapun proses dalam ekstraksi tersebut, antara lain: 1) Timbang bahan baku dengan takaran 500 gr/ 5 liter; 2) Buah Naga/kulit buah naga dipotongpotong dan diekstraksi hingga 2,5 liter 
sehingga diperoleh $\mathrm{pH}$ yang tepat sekitar 7,5. Hal ini untuk memperoleh zat warna dari bahan baku buah Naga.; 3) Saring zat warna tersebut, seteleh dingin dapat dilakukan pewarnaan; 4) Kain dimasukkan dalam zat warna alami selama 15-30 menit; 5) Angkat kain setelah pencelupan dan dijemur sampai agak atus; 6) Lanjutkan pada tahap fiksasi.

\section{Fiksasi}

Yaitu proses dalam mengunci warna agar warna tidak mudah luntur dan berfungsi untuk membangkitkan warna. Proses dalam fiksasi, antara lain : 1) Larutkan zat fiksasi kapur, tawas, tunjung, jeruk nipis, gula jawa dalam takaran $50 \mathrm{gr} /$ liter air dari masing-masing fiksasi; 2) Direndam masing-masing fiksasi dalam waktu 1 malam; 3) Pagi hari ambil larutan bening dari masing-masing fiksasi tersebut; 4) Larutan fiksasi siap digunakan; 5) Kain dimasukkan dalam larutan fiksasi selama 10 menit; 6) Angkat tunggu selama 5 menit kemudian dibilas dan dikeringkan. Selesai proses dalam pewarnaan zat warna alami.

\section{Pencucian}

Pada proses pencucian ini dilakukan untuk menghilangkan warna yang tidak menempel pada kain yang akan mengakibatkan terjadinya warna yang tidak merata. Dengan pencucian maka warna yang tidak menempel akan hilang dari kain dan warna kain menjadi rata.

\section{Pengambilan Sampel}

Pengambilan sampel dilakukan untuk diujikan pada uji ketahanan luntur sinar matahari dan uji ketahanan luntur cuci sabun. Pengambilan sampel ini dilakukan dengan menentukan hasil pewarnaan yang tepat sebagai sampel. Pada sampel yang dipilih yaitu sampel yang warnanya memiliki hasil warna yang rata dalam artian tidak terjadi warna yang belang.

\section{Hasil Uji Ketahanan Luntur Sinar Matahari dan Uji Ketahanan Luntur Cuci Sabun}

Uji ketahanan luntur warna yaitu suatu pengujian yang dilakukan untuk mengetahui tingkat kekuatan warna yang diperoleh setelah dilakukan pengujian. Pada pengujian luntur warna ini menggunakan uji sinar matahari dan uji ketahanan luntur cuci sabun. Alat yang digunakan pada pengujian tahan luntur warna terhadap sinar matahari dan uji cuci sabun adalah (gray schale) skala abu-abu. Dalam pengujian ketahanan luntur warna terdapat tingkat nilai, adapun tingkat nilai tersebut :

Tabel 1. Evaluasi Tahan luntur Warna

\begin{tabular}{ccc}
\hline No & Nilai Tahan Luntur Warna & Evaluasi Tahan Luntur Warna \\
\hline 1. & 5 & Baik sekali \\
\hline 2. & $4-5$ & Baik \\
\hline 3. & 4 & Baik \\
\hline 4. & $3-4$ & Cukup Baik \\
\hline
\end{tabular}




\begin{tabular}{lcc}
\hline 5. & 3 & Cukup \\
\hline 6. & $2-3$ & Kurang \\
\hline 7. & 2 & Kurang \\
\hline 8. & $1-2$ & Jelek \\
\hline 9. & 1 & Jelek \\
\hline
\end{tabular}

Tabel 2. Hasil Pengujian Tahan Luntur Warna Terhadap Sinar Matahari

\begin{tabular}{|c|c|c|c|c|c|}
\hline \multirow{2}{*}{ No } & \multirow{2}{*}{ Jenis Bahan } & \multirow{2}{*}{ Fiksasi } & \multicolumn{3}{|c|}{ Hasil Uji } \\
\hline & & & Warna & Angka & Keterangan \\
\hline \multirow[t]{3}{*}{1.} & $\begin{array}{l}\text { Buah Naga / Dragon } \\
\text { Fruit }\end{array}$ & Tunjung & Krem kekuningan & 5 & Baik sekali \\
\hline & & Kapur & $\begin{array}{l}\text { Krem Muda hampir } \\
\text { putih }\end{array}$ & 5 & Baik sekali \\
\hline & & Eksrak tunjung & Krem coklat muda & 5 & Baik sekali \\
\hline \multirow[t]{2}{*}{2.} & Kulit Buah Naga & Tunjung & $\begin{array}{l}\text { Krem coklat kuningan } \\
\text { tua }\end{array}$ & 5 & Baik Sekali \\
\hline & & Gula Jawa & Krem muda & 5 & Baik Sekali \\
\hline
\end{tabular}

Tabel 3. Pengujian Tahan Luntur Warna Terhadap Uji Cuci Sabun

\begin{tabular}{|c|c|c|c|c|c|}
\hline \multirow{2}{*}{ No } & \multirow{2}{*}{ Jenis Bahan } & \multirow{2}{*}{ Fiksasi } & \multicolumn{3}{|c|}{ Hasil Uji } \\
\hline & & & Warna & Angka & Keterangan \\
\hline \multirow[t]{6}{*}{1.} & Buah Naga & Tunjung & Krem kekuningan & 4 & Baik \\
\hline & & Jeruk Nipis & Putih kekuningan & 2 & Kurang \\
\hline & & Kapur & Putih kekuningan & 3 & Cukup \\
\hline & & $\begin{array}{l}\text { Ekstrak Gula } \\
\text { Jawa }\end{array}$ & Krem muda & $3-4$ & Cukup baik \\
\hline & & Ekstrak Kapur & Putih kekuningan & $3-4$ & Cukup Baik \\
\hline & & $\begin{array}{l}\text { Ekstrak } \\
\text { Tunjung }\end{array}$ & Krem kekuningan & 4 & Baik \\
\hline \multirow[t]{2}{*}{2.} & $\begin{array}{l}\text { Kulit Buah } \\
\text { Naga }\end{array}$ & Tunjung & Krem kekuningan & 4 & Baik \\
\hline & & Tawas & putih kekuningan & 2 & Kurang \\
\hline
\end{tabular}

Hasil uji dari masing-masing perlakukan menunjukkan nilai yang berbeda-beda nilai yang diperoleh pada ketahanan luntur sinar matahari menunjukkan nilai 5 yang artinya bahwa nilai tersebut baik sekali. Hal ini terdapat pada jenis bahan :

1. Buah Naga dengan fiksasi tunjung dengan hasil warna krem kekuningan dengan score 5 yang menunjukkan bahwa ketahanan luntur warna baik sekali.

2. Buah Naga dengan fiksasi kapur hasil warna krem muda hampir putih dengan score 5 yang menunjukkan bahwa ketahanan luntur warna baik sekali.

3. Buah Naga Ekstraksi dengan fiksasi tunjung hasil warna krem coklat muda dengan score 5 menunjukkan bahwa ketahanan luntur warna baik sekali. 
4. Kulit Buah Naga dengan fiksasi tunjung hasil warna krem coklat kekuningan tua dengan score 5 menunjukkan bahwa ketahanan lunturnya baik sekali.

5. Kulit Buah Naga dengan fiksasi Gula Jawa hasil warna krem muda dengan score 5 menunjukkan bahwa ketahanan lunturnya baik sekali.

Hasil pengujian pada uji Pencucian sabun menunjukkan bahwa :

1. Jenis bahan Buah Naga dengan fiksasi tunjung warna yang dihasilkan krem kekuningan dengan score 4 menunjukkan ketahanan luntur baik.

2. Buah Naga dengan fiksasi jeruk nipis warna yang dihasilkan putih kekuningan dengan score 2 menunjukkan ketahanan luntur kurang.

3. Buah Naga dengan fiksasi kapur warna yang dihasilkan putih kekuningan dengan score 3 menunjukkan ketahanan luntur cukup.

4. Buah Naga ekstraksi dengan fiksasi gula jawa warna yang dihasilkan krem muda dengan score 3 - 4 menunjukkan ketahanan luntur cukup baik.

5. Buah Naga ekstraksi dengan fiksasi kapur warna yang dihasilkan putih kekuningan dengan score 3- 4 menunjukkan ketahanan luntur cukup baik.

6. Buah Naga Ekstraksi dengan fiksasi tunjung warna yang dihasilkan krem kekuningan dengan score 4 menunjukkan ketahanan luntur baik.

7. Kulit buah Naga dengan fiksasi tunjung warna yang dihasilkan krem kekuningan score yang diperoleh 4 menunjukkan ketahanan luntur baik.
8. Kulit buah Naga dengan fiksasi tawas warna yang dihasilkan putih kekuningan score yang diperoleh 2 menunjukkan ketahanan luntur kurang.

\section{PENUTUP}

1. Hasil warna yang diperoleh menunjukkan warna krem kuningan dan warna putih kekuningan .

2. Hasil pengujian sinar matahari memiliki score 5 yang menunjukkan ketahanan luntur baik sekali yaitu terdapat pada bahan buah Naga dengan fiksasi tunjung, kapur, bahan buah Naga melalui ekstraki dengan fiksasi tunjung, bahan buah Naga melalui ekstrasi dengan fiksasi gula jawa, bahan buah Naga melalui ekstrasi dengan fiksasi kapur.

3. Hasil pengujian pencucian sabun memiliki score yang bervariasi. Hal ini dapat di tunjukkan dengan :

a. Bahan buah Naga fiksasi tunjung dengan angka 4 menunjukkan keterangan baik.

b. Bahan buah Naga dengan fiksasi jeruk nipis dengan score 2 keterangan kurang.

c. Bahan buah Naga dengan fiksasi kapur menunjukkan score 3 dengan keterangan cukup.

d. Bahan buah Naga melalui ekstrasi dengan fiksasi gula jawa menunjukkan score 3-4 dengan keterangan cukup baik.

e. Bahan buah Naga melalui ekstraksi dengan fiksasi kapur menunjukkan score 3-4 keterangan cukup baik.

f. Bahan buah Naga melalui ekstraksi dengan fiksasi tunjung menunjukkan score 4 dengan keterangan baik. 
g. Bahan kulit buah Naga dengan fiksasi tunjung menunjukkan score ke 4 dengan keterangan baik.

h. Bahan kulit buah Naga dengan fiksasi tawas dengan score 2 keterangan kurang.

4. Hasil bahan yang melalui pengekstrakan dengan warna yang tidak melalui bahan pengekstrakkan terkandung warna yang berbeda tetapi pada warna yang diekstrak akan memunculkan warna yang lebih kuat dan warna lebih pekat.

\section{A. Saran}

Tiap bulan terdapat tanaman yang tumbuh secara musiman, hal ini dapat digunakan untuk menentukan tren warna alami berdasarkan alam atau tumbuhan alam pada musim - musim tertentu.

\section{DAFTAR PUSTAKA}

Brotowidjoyo, Mukayat D. 1991. Metodologi Penelitian dan Penulisan Karangan Ilmiah. Yogyakarta: Liberty.

Hadiwijaya, Kusnan. 1975. Pengetahuan Bahan dan Teknik Batik Indonesia. Yogyakarta: Balai Pengembangan Kerajinan dan Batik.

Hanum, Farida. 2002. Proses Pengolahan Air Sungai Untuk Keperluan Air Minum. Fakultas Teknik Program Studi Teknik Kimia Universitas Sumatera Utara.

Hasanudin, M. Dkk. 2001. Laporan Penelitian Penerapan Zat Warna dan Kombinasinya pada Produk Batik dan Tekstil Kerajinan. Yogyakarta: Balai Besar Penelitian dan Pengembangan Industri Kerajinan dan Batik.

Khayati, Eni Zuhni. 1997. Ilmu Tekstil. Yogyakarta: FPTK IKIP YOGYAKARTA.

Kristanto, Daniel. 2010. Buah Naga Pembudidayaan di Pot dan di Kebun. Cetakkan Ke- 4. Jakarta: Penebar Swadaya.

Mulyono, Anton M. 1990. Kamus Besar Bahasa Indonesia.

Sudiatso, Sugeng. 1999. Studi Kultivsi Tanaman Tarum (Indigofera Arrecta Hochst), Makalah, Yogyakarta: Dekranas DIY.

Surachmad, Winarno. 1975. Dasar dan Teknik Research Pengantar Metodologi IImiah. Bandung: C. V. "TARSITO".

\section{Webtografi}

http://lordbroken.wordpress.com/2 011/4/3/pembuatan gula jawa

http://www.scribd.com/Asam Sitrat. 
Tabel. Hasil Sampel Eksperimen

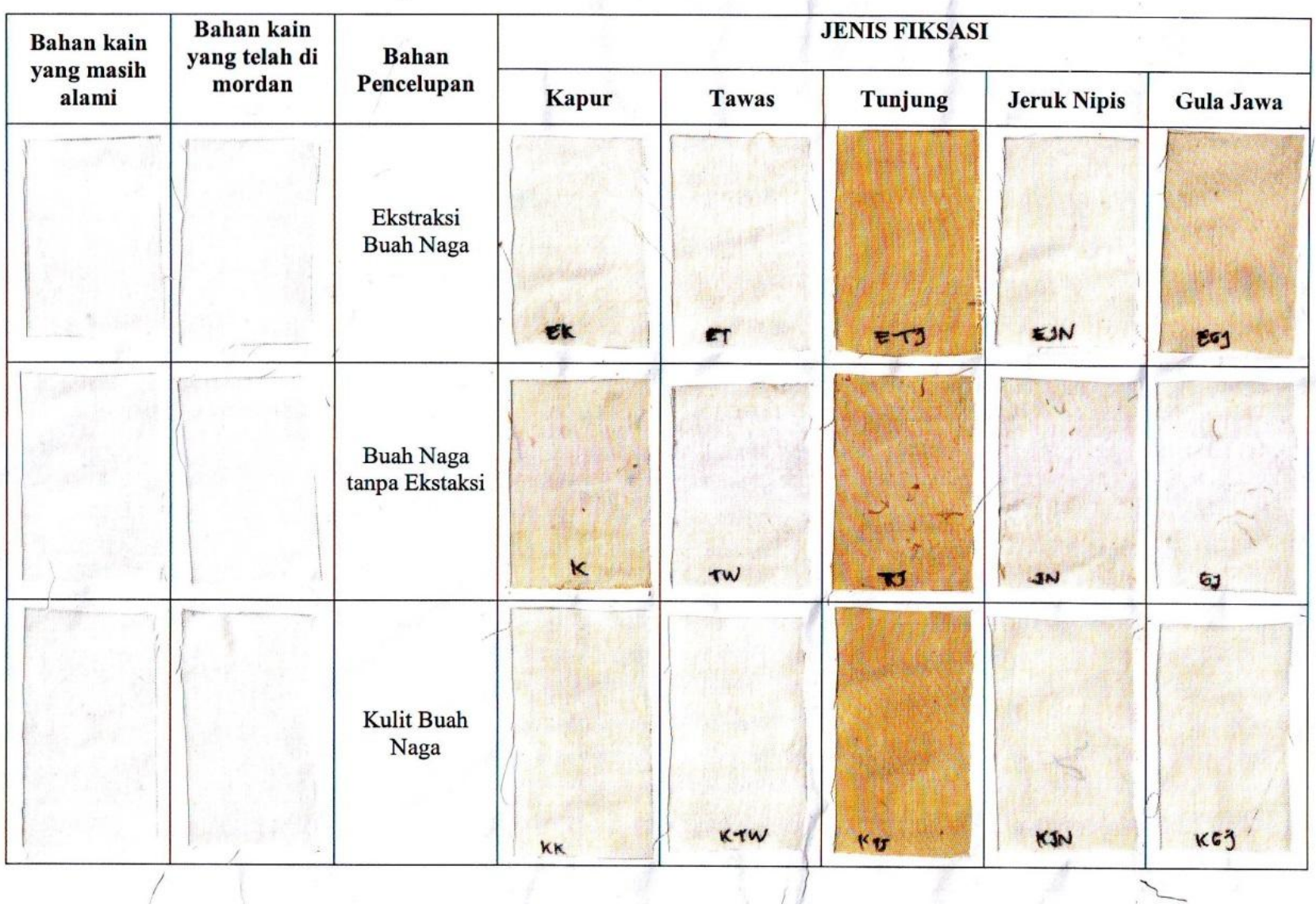

